\title{
Medikaliseringen av det psykosociala fältet. Om en kunskapssammanställning från Socialstyrelsen, IMS
}

\author{
ALAIN TOPOR
}

Tecknen på en medikalisering av det psykosociala fältet har ökat under senare tid. Denna artikel undersöker denna medikaliseringsprocess utifrån Socialstyrelsens kunskapssammanställning "Effekter av psykosociala insatser för personer med schizofreni och bipolär sjukdom", som ska resultera i riktlinjer för socialtjänsten.

\section{En kunskapssammanställning}

2004 fick Institutet för utvärdering av Metoder i Socialt arbete (IMS) uppdraget från Handikappenheten inom Socialstyrelsen (SoS) att redovisa kunskap om »effekt av psykosociala insatser för personer med svåra psykiska funktionshinder" (Socialstyrelsen 2006a, s. 3). ${ }^{1}$ IMS:s uppdrag var även watt göra en genomgång av kunskapsläget som en grund för att formulera riktlinjer inom detta område» (s. 3). 2006 publicerade IMS/SoS en slutrapport: „Effekter

Alain Topor, docent, psykolog, FoU-enheten, Psykiatri Södra Stockholm och Institutionen för Socialt Arbete, Stockholms Universitet av psykosociala insatser för personer med schizofreni eller bipolär sjukdom - En sammanställning av systematiska översikter».

En trolig bakgrund till beställningen är att det i samband med minskningen av den slutna psykiatriska vårdens omfattning utvecklades ett antal verksamheter inom

1 Begreppen och beteckningar på enheter inom olika verksamheter kan ha förändrats sedan den granskade kunskapssammanställningen publicerades. Handikappenheten heter till exempel idag Enheten för funktionshindersfrågor. Jag har valt att i möjligaste mån behålla namnen i deras dåvarande betydelse och lydelse. Alla hänvisningar där referens inte närmare anges är till Socialstyrelsens skrift från 2006 
kommun och landsting som fokuserade på brukarnas boende, fritid, sysselsättning och rehabilitering ute i samhället. Sociala metoder och samhällsvetenskaplig forskning fick en plats i psykiatrins fält. Framväxten av dessa verksamheter var ojämn över landet och deras huvudmannatillhörighet var en följd av lokala tillfälligheter (SoS 1998). De kom också att få olika beteckningar såsom mellanvård och socialpsykiatriska verksamheter. I samband med psykiatrireformen 1995, kom merparten av dessa verksamheter att förläggas till »socialpsykiatriska enheter" och inom "handikappomsorgen« i kommunerna. Dessa olika beteckningar har utsatts för kritik och i samband med den Nationella Psykiatrisamordningens verksamhet lanserades istället begreppet "psykosociala insatser» för att beteckna verksamheterna inom detta område och deras insatser (SoU 2006). Begreppet psykosociala insatser hade redan använts, men med en helt annan, psykodynamisk, innebörd inom socialt arbete (se Hessle 1985, Lennéer Axelsson \& Thylefors 1999). I mitten på 2000-talet skapades ett nationellt "Centrum för Evidensbaserade Psykosociala Insatser (CEPI). Innehållet $\mathrm{i}$ "psykosociala insatser " har dock förblivit oklar.

Kunskapssammanställningen bygger på ett urval av forskningen om vissa insatser som uppgivits vara "psykosociala» och som utvärderats med hjälp av forskningsmetoder som anges i Socialstyrelsens riktlinjer för evidensgradering (2004). Expertgruppen har genomfört en bred sökning i åtta olika databaser med medicinsk, psykologisk och social inriktning. Sammanlagt fick de 1926 träffar. De fulltextgranskade 108 av dem, exkluderade 77 och fick 31 studier kvar. De finner en stark evidens för vissa insatser som "supported employment", vissa former av "familjeinterventioner" och "Case management" inom ramen för en "ACT-modell» när det gäller "personer med schizofreni« (s. 97), men också ett stort behov av fortsatt forskning.

I slutet av sitt arbete påtalar Expertgruppen »en eftersläpning av kunskapsläget» (s. 99). De studier som man har sammanställt återspeglar redan gamla och eventuellt passerade förhållanden (Burns 2009). Denna eftersläpning tillspetsas när det gäller framtagning av de nationella riktlinjer, som skall basera sig på den redan föråldrade kunskapssammanställningen. Riktlinjerna har inte offentliggjorts tre år efter att kunskapssammanställningen publicerats. Sammanställningens avslutande sammanfattning lyder:

"Sammanfattningsvis visar vår genomgång på ett spektrum av psykosociala insatser som det kan finnas behov av och det är angeläget att beakta att de medicinska och psykosociala insatserna koordineras utifrain individuella behov."(s. 104)

\section{Medikaliseringen av det psykosociala fältet}

I följande artikel analyseras Socialstyrelsens kunskapssammanställning. En central aspekt som problematiseras är den medikalisering av sitt uppdrag som expertgruppen bakom rapporten genomfört. Medikalisering definieras av Johannisson $(1990$, s. 7) som »viljan att muta in livsvärldens feno- 
men inom medicinens domän«. Conrad och Schneider (1992, s. 29) skriver om »how medical definitions of deviant behavior are becoming more prevalent in modern industrial societies like our own«. Denna medikaliseringsprocess innebär att människors handlingar isoleras från sitt sociala sammanhang och omvandlas till symptom som den medicinska professionen kan observera och gruppera i diagnostiska kategorier som sägs motsvara faktiskt existerande sjukdomar, även om inga biologiska förändringar kan noteras hos individen. Nästa steg blir att utveckla specifika behandlingsmetoder för var och en av dessa sjukdomar/ diagnoser. Medikaliseringen handlar alltså inte enbart om att den medicinska professionen ges företräde till olika aspekter av livet, utan även om hur dessa aspekter skall definieras, studeras och hanteras. I denna artikel tas fyra aspekter av denna medikalisering upp:

\section{Expertgruppens sammansättning}

2. Omdefinition av uppdraget

3. Begreppsapparat

4. Val av forskning som redovisas

\section{Expertgruppens medicinska bas}

Det psykosociala fältet är sammansatt och har oklara avgränsningar. Tar vi begreppet psykosocialt bokstavligen, hänvisas vi till vetenskap såsom socialt arbete, psykologi, antropologi, sociologi, etnologi, idéhistoria $\mathrm{mm}$. Problemen med avgränsningarna av det psykosociala fältet märks i rapportens tillblivelsehistoria inom Socialstyrelsen.
Utgångspunkten för rapporten är att Handikappenheten vänder sig till en enhet inom samma myndighet, IMS, som arbetar med sociala metoder. Denna enhet kontrakterar i sin tur en grupp för att genomföra uppdraget. Vilka får då i uppdrag att genomföra studien?

Projektledare blir en professor i psykosocialt arbete anställd vid Avdelningen Psykiatri vid Institutionen för kliniska vetenskaper. Projektledaren har samlat en "expertgrupp» till sitt förfogande. "Expertgruppens« sammansättning är av intresse. Den består av en professor i vårdvetenskap, en psykiater tillika docent samt en doktorand från projektledarens institution. Det är alltså en grupp med en i huvudsak medicinsk inriktning som genomför uppdraget. Samtliga är knutna till medicinska fakulteter. Deras kontakter på IMS är i första hand en socionom och en sociolog. För dem anges ingen akademisk titel i rapporten, vilket tyder på att de saknar akademiska forskningskvalifikationer.

I rapportens förord uppges att en preliminär version granskats av "sakkunniga personer inom området» (s. 3). Även bland dessa sakkunniga finns en tydlig medicinsk dominans. Två av de sakkunniga är professorer tillika psykiatrer, ytterligare en är professor och knuten till en medicinsk fakultet. Den sista personen bland de sakkunniga saknar helt och hållet titel i presentationen.

Arbetet med denna kunskapssammanställning av insatser inom det psykosociala fältet domineras alltså av personer med hög, men främst medicinsk, kompetens eller institutionell bas. Inga professorer eller docenter från någon institution för 
socialt arbete, psykologi eller sociologi har kopplats till arbetet. Att bilda en grupp med en sådan homogenitet innebär en risk för ensidighet i valet av förutsättningar för att genomföra uppdraget. Ett grundläggande krav på kritisk distans till det egna studieobjektet kan lätt försvinna i den konstruerade samstämmigheten.

Kunskapssammanställningen bär tydliga spår av en strävan till genomskinlighet i urvalsprocessen av de studier och metastudier som presenteras. Det är en lovvärd ambition. Det är dock mycket svårt för en enskild läsare att granska urvalet på ett grundligt sätt, då ett sådant arbete skulle kräva betydande resurser. Därför är det beklagligt att expertgruppen byggts upp på ett monolitiskt sätt (Sundgren 2007). Det utgör en allvarlig risk för dess vetenskapliga ambition och trovärdighet. Luborsky och hans medarbetare (1999) har visat att resultaten av prövningen av olika metoder var starkt beroende av forskarens "allegiance", det vill säga ideologisk knytning till en av de metoder som studerades.

Rapporten har alltså vandrat från en enhet specialiserad på funktionshinder till en annan som skall syssla med sociala metoder för att landa i ett medicinskt fält med oklara konturer. Det professionella fältet som sammanställningen fokuserar på och riktar sig till är dock socialtjänsten: „En sådan genomgång skulle kunna ge socialtjänsten underlag för förbättring i arbetet med gruppen« (s.15).

På grundval av kunskapsgenomgången håller nu Socialstyrelsen på att "utarbeta riktlinjer kring psykosociala insatser för gruppen psykiskt funktionshindrade» (s. 15). Mot denna bakgrund är det viktigt att granska den kunskapssammanställning som producerats.

\section{En medikalisering av uppdraget}

Den aldrig problematiserade omdefinitionen av målgruppen för kunskapssammanställningen som expertgruppen genomförde kan ses som ett uttryck för den medicinska dominansen i expertgruppen.

\section{Frain funktionshindertill medicinsk diagnos}

Inom det sociala fältet och inom forskningen om funktionshinder finns en rad sätt att indela individer med psykiska problem som är i behov av stöd och hjälp. Kunskapssammanställningen vilar inte på någon av dessa. Redan i sin titel visar sig rapporten vila på en medicinsk grund; den psykiatriska diagnostiken. Följaktligen handlar rapporten till SoS:s Handikappenhet inte om personer med psykiska funktionshinder, utan om "personer med schizofreni och bipolär sjukdom».

Denna medikalisering av definitionen av målgruppen kan uppfattas som en precisering och därmed ett sätt att öka rapportens stringens. Men den psykiatriska diagnostiken är en klassificering av »sjukdomar" som baserar sig på symptom inom individen och inte av exempelvis de fenomen i omgivningen som omvandlar funktionsnedsättning till funktionshinder. 


\section{Från diagnoser till svåra störningar}

Undersöker man hur expertgruppen bakom kunskapssammanställningen handskats med denna diagnostiska bas uppstår ytterligare problem. Redan i rapportens inledning vidgas den brukargrupp som kunskapsgenomgången undersöker från specifika diagnosgrupper till det som benämns "severe mental illness" (s. 23). Härmed sprängs den diagnostiska grundvalen till undersökningen. Det är dock oklart vad den ersätts med. Sandlund (2005) exempelvis skriver om "severe mental illness" att: "Definitionerna av dessa begrepp varierar dock, med starkt lokal prägel« (s. 18). I rapporten påstår författarna att "allvarliga psykiska störningar" förutom schizofrenidiagnosen omfattar även "personer med olika psykossjukdomar" (s. 23).

Vanligtvis inbegriper dock begreppet "severe mental illness" inte bara personer med "schizofreni och bipolär sjukdom" utan även "olika psykossjukdomar". I Socialstyrelsens Författningssamling (SOSFS 2000:12 s. 3) anges följande tillstånd som allvarliga psykiska störningar:

- "psykos (...),

- Depression med självmordsrisk,

- Svår personlighetsstörning med impulsgenombrott av psykotisk karaktär eller annan psykotisk episod,

- Svår psykisk störning med starkt tvångsmässigt beteende."

De olika studier som sammanställs i kunskapsgenomgången kan ha andra avgräns- ningar, men om det kan vi inget veta. Detta ställer oss inför ett avgörande problem då en vanlig föreställning bakom den medicinska modellen och den diagnostiska kulturen är att varje diagnos representerar en välavgränsad sjukdom. Varje sjukdom har sin specifika etiologi och därmed en lika specifik behandling. Att övergå från specifika diagnoser till ett oklart begrepp som »severe mental illness» innebär i praktiken att man upplöser hela den rationella logiken bakom den medicinska modellen. Den precisa diagnostiska grunden på rapportens omslag upphävs inom rapportens pärmar och det blir omöjligt att veta för vilka tillstånd/diagnoser de evidensbaserade insatser som sammanställningen tar fram är evidensbaserade.

\section{Diagnosernas skenbara klarket}

Trots att kunskapssammanställningen nu visat sig inte längre handla om några specifika diagnoser fortsätter expertgruppen att skriva som om den kunskap de presenterar handlar specifikt om "schizofreni och bipolär sjukdom». Skulle vi ändå acceptera expertgruppens utgångspunkt att bygga upp rapporten kring specifika diagnoser uppstår andra problem. Dessa problem kan vara värda att exemplifiera då de problematiserar det objektiva skimret som omger psykiatriska diagnoser och medikaliseringsförsöken av det sociala arbetets fält.

"Schizofreni« är en diagnos som har utsatts för en omfattande vetenskaplig kritik (Bentall 1990, 2003, Kirk \& Kutchins 
1992, Boyle 2002, Read 2004a). Kritiken har riktat sig mot att diagnosen schizofreni:

- Saknar validitet.

- Omfattar patienter som kan ha ett stort antal olika symptomkombinationer.

- De olika diagnosmanualer som är i bruk skiljer sig på viktiga punkter när det gäller kriterier för att en patient skall få den diagnosen.

Avgränsningen mellan schizofrenin och bipolär sjukdom har också problematiserats och även ifrågasatts.

Kunskapssammanställningen vänder sig specifikt till socialt arbete. Därför hade det varit motiverat av både vetenskapliga och pedagogiska skäl att inkludera samhällsvetenskaplig forskning i genomgången och kritiskt analysera de egna begreppen och avgränsningarna (Bourdieu 2004).

Denna forskning hade dock betydligt försvårat skapandet av bilden av en oomtvistad kunskap där fokus helt och hållet är lagt på hur de psykosociala insatserna utvärderats och inte på förutsättningarna för urvalet av just dessa studier.

\section{Från självupplevda besvär till sjukdom}

Den medicinska utgångspunkten för kunskapssammanställningens författare återspeglas även i bruket av sjukdomsbegreppet och det är inget oskyldigt val. Exempelvis har den amerikanska psykiatriska föreningen valt att använda sig av begreppet "disorder" (svenska "störning") i sin diagnosmanual, för att markera bristen på kunskap om de psykiska störningarnas bakgrund (APA 1994). I den svenska Nationalencyklopedin (1994) skriver Ottosson att:

"Psykisk störning, tillstånd kännetecknat av avvikelser $i$ upplevelser och beteenden. Termen psykisk störning har numera fätt ersätta psykisk sjukdom för att markera att ett biologiskt underlag inte kan paivisas vid en del av de tillstånd som faller inom psykiatrins verksamhetsområde."

Bruket av sjukdomsbegreppet är desto mer värt att beklaga då det förekommer i en rapport som handlar om psykosociala metoder. Det vilar på en föreställning om att psykiska störningar är medicinska åkommor och att psykosociala faktorer inte kan ha något primärt förklaringsvärde till dessa störningars uppkomst och att psykosociala insatser och omständigheter inte kan leda till återhämtning eller definieras som behandling. Även detta är ett ställningstagande som borde ha diskuterats.

\section{Psykosociala insatser?}

Låt oss nu undersöka hur expertgruppen operationaliserat uppdragets fokus: de psykosociala insatserna. Under rubriken "Insatser som ingåru kan man läsa en lista över dessa insatser. Expertgruppen presenterar inte någon diskussion om dessa begrepp eller en beskrivning av hur de har gått tillväga i sitt urval av insatser. Bristen på tydlighet bidrar till att skapa en bild av rapportens ämne som oproblematisk, vilket det knappast är. En diskussion om innehållet i det psykosociala fältet hade dock 
behövts då listan på psykosociala insatser som behandlas i rapporten innehåller dels oväntade inslag och dels saknar andra inslag, som man kunde ha förväntat sig att finna där.

Bland de mer oväntade psykosociala insatserna som tas upp kan nämnas "psykoterapi«, där kognitiv beteendeterapi är den ena och psykodynamiska terapier den andra. Likaså kan det knappast vara självklart att inkludera "compliance» eller "följsamhet", som definieras med i vilken utsträckning individen följer de råd och ordinationer som han/hon har fått av sjukvården bland "psykosociala insatser".

$\AA$ andra sidan saknas centrala aspekter hos många individinriktade insatser där forskningen visat stor effekt. Till exempel så finns det i dag en omfattande forskning som pekar på att det inte är de olika specifika terapeutiska teknikerna som spelar en huvudroll för deras eventuella effektivitet i den kliniska praktiken. Istället finns ett betydande stöd för hypotesen att gemensamma, psykosociala faktorer, som till exempel den relation och allians som kan uppstå mellan brukaren och behandlingspersonal, kan vara en huvudförklaring till många olika insatsers framgångar. En omfattande forskning stödjer denna hypotes (Wampold 2001, Lambert 2004, Mc Cabe \& Priebe 2004, Johansson 2006, Denhov 2007).

Ett systematiskt genomfört köns-/ gender perspektiv hade också varit befogat i ett fält som så länge förbisett denna aspekt (Read 2004b, Schön 2009).

Återhämtningsforskningen har pekat på en tämligen konstant nivå av återhämtning under hela 1900-talet bland brukare som fått en schizofrenidiagnos och därmed under olika behandlingsepoker (Bleuler 1978, Warner 1985, Harding \& Keller 1998). Detta ifrågasättande av behandlingarnas betydelse för återhämtningen har lett till en rad studier om hjälpande faktorer vid återhämtning från en rad olika diagnosgrupper såsom svåra psykiska störningar (Davidson 2003, Topor 2004, Schön et al. 2009), missbruk (Blomkvist 1999), depression (Schreiber 1996) och ätstörningar (Pettersen 2007). Faktorer av psykosocial karaktär som uppmärksammats i denna forskning, men som förbigås med tystnad $\mathrm{i}$ expertrapporten, är exempelvis brukarnas egna hanteringsstrategier (Lee et al. 1993, ), vardagligt stöd av anhöriga och vänner (Denhov 2002, Blomkvist 1996), professionella som utvecklar nya former av professionalitet som bygger på nära relationer till brukarna (Denhov 2000a \& b, Topor 2004, Borg \& Kristianssen 2004, Topor et al. 2006) samt vardagsvillkor (Davidson \& Borg 2008).

En annan väl beforskad psykosocial insats som inte heller tas med i rapporten är placebo. I en rad randomiserade kontrollerade studier (RCT) består en av insatserna av en "icke verksam" insats, vars resultat kontrasteras mot den studerade insatsen. Denna forskning visar att "icke verksamma" insatser kan vara ytterst verksamma (Elkin et al. 1989, Åsberg 2000, Turner et al. 2008).

Ytterligare en faktor som kan ha betydelse för brukarnas psykiska (o)hälsa och återhämtning är deras privatekonomi. Dålig ekonomi kan vara en viktig faktor som förhindrar återhämtning från svåra psykiska störningar (Topor 2004, Mattsson et 
al. 2008). Ett ekonomiskt tillskott har i en RCT visat sig kunna få en positiv effekt för såväl symptombilden som funktionsnivån och livstillfredsställelsen (Davidson et al. 2001 a \& b, 2004).

Men placebo och ekonomiskt bistånd uppfattas sällan som "insatser" inom en medicinsk psykiatri och mellanmänskliga relationer och brukarnas egna ansträngningar låter sig inte definieras som »insatseru, så har det psykosociala fältet reducerats på ett självsvåldigt och oproblematiserat sätt.

\section{Psykosociala faktorer eller individualiserade insatser}

Begränsningen av det psykosociala till »insatser« är inte ovanlig inom det psykiatriska fältet. Insatser är i detta sammanhang underförstått avgränsade individuella professionella insatser. Det psykosociala fältet är dock betydligt vidare än den del som kan beskrivas i termer av sådana insatser. Det individualiserade perspektivet skapar en annan oproblematiserad begränsning för kunskapssammanställningen.

"Insatserna som inkluderas $i$ denna sammanställning skall rikta sig direkt eller indirekt till den person som tillhör målgruppen. Med detta menas att insatsen har som mål att uppnå en specifik effekt hos den enskilde individen vilket även kan ske indirekt genom till exempel pedagogiska insatser till närstående."(s. 24)

På grund av denna avgränsning utesluts socialpolitiska beslut som direkt och indi- rekt påverkar symptomen, funktionsnivån, levnadsvillkor och livskvaliteten för människor med psykiska funktionshinder.

Inom det psykosociala fältet är det dock möjligt att inbegripa beslut om insatser, såsom privatiseringen av det allmännyttiga bostadsbeståndet och indragningen av subventioner till bostadsbyggandet som torde framkalla segregering och hemlöshet bland svaga grupper, eller arbetslöshetsnivån, eller sänkningen av ersättningsnivåerna för långtidssjukskrivna som genomförts på senare tid och den betydande relativa minskningen av den disponibla inkomsten bland personer med diagnosen schizofreni, som Socialstyrelsen påvisat (Socialstyrelsen 2006b).

Det finns exempel på att den typen av faktorer har undersökts. Till exempel pekar Warner (1985) på ett statistiskt samband mellan arbetslöshetens omfattning och sannolikheten för människor som fått diagnosen schizofreni att återhämta sig.

Det finns även mycket som talar för att de stora farsoternas härjningar, som exempelvis TBC och koleran, begränsades först genom socialpolitiska åtgärder, långt innan effektiva behandlingsmetoder tagits fram (Illich 1975). Därför finns det skäl att inte begränsa vår kunskap på det psykiatriska fältet till avgränsade individuella insatser.

\section{"Sedvanlig"vård?}

Valet av insatser blir än mer problematisk när man i expertgruppens diskussion kan läsa att: "De insatser som bedömts i denna sammanställning sker i tillägg till sedvanlig 
vård och behandling där medicinering är en av flera basinsatser" (s. 103).

"Sedvanlig vård" är ett problematiskt begrepp. Det torde råda stora skillnader mellan "sedvanlig vård" i USA, där vårdutbudet är starkt beroende av individens ställning på försäkringsmarknaden, och i Sverige med sitt allmänna försäkringssystem och omfattande satsning på lika vård för alla medborgare. Även inom Sveriges gränser från ett landsting till ett annat, från en mottagning till en annan, finns avsevärda skillnader mellan det behandlingsutbud som brukare med samma problematik erbjuds.

I kunskapssammanställningen omnämns de problem som det medför att "flertalet studier" (s. 99) som ingår i sammanställningen är gjorda i länder vars socialpolitiska villkor skiljer sig från varandra och från de svenska. USA och Kina nämns i texten. Hur generaliserbara är dessa studiers slutsatser till en svensk vardag? Frågan ställs i expertgruppens diskussion. Svaret är att detta bör "diskuteras och övervägas. Implementeringsstudier i Sverige av insatser med starkt stöd i internationell litteratur bör ges prioritet « (s. 100). Innebär denna reservation att kunskapssammanställningens presentation av insatser med stark evidens i dag inte kan ligga till grund för allmänna riktlinjer i Sverige, utan att expertgruppen istället förordar en försiktig prövoperiod med vetenskaplig uppföljning?

\section{Från effekt till effektivitet}

Utan att gå in i en granskning av de studier som ingår i kunskapssammanställningen är det ändå möjligt att ytterligare problematisera expertgruppens utgångspunkter.

Att likställa resultatet av psykosociala insatser inom vardagspraktiken inom psykiatrin och socialtjänsten ("Efficiency») med effekten av psykosociala insatser i randomiserade kontrollerade studier ("Efficacy") är inte självklart (Lambert \& Ogles 2004). Det förekommer olika uppfattningar inom det vetenskapliga och det praktiska fältet om vad som är bästa möjliga vårdutbud. Många forskare menar också att sammansatta verksamheter inte kan bedömas med hjälp av RCT (Thornicroft \& Tansella 2002). Det torde vara ett krav att en statligt initierad kunskapsgenomgång förhåller sig till de olika strömningarna som förekommer i det fält de studerar (se debatten i Socialvetenskaplig tidskrift; Antilla 2007a \& b , Bergmark \& Lundström 2006, 2007 a $\&$ b, Hydén 2008).

Det finns inte några studier som visar att psykiatriska och sociala verksamheter som endast tillämpar evidensbaserade insatser i expertgruppens mening skulle vara mer effektiva än andra.

Frågan om insatsers effekt eller effektivitet har ytterligare en sida. Vi skall nu beröra den tredje aspekten i expertgruppens operationalisering av sitt uppdrag: insatsernas effekter: "... att bedöma och redovisa det vetenskapliga kunskapsunderlaget för effekter av psykosociala insatser för personer med svåra psykiska funktionshinder" (s. 3).

Uppdraget handlar alltså inte om att finna de mest effektiva psykosociala insatserna under experimentella omständigheter, utan effekter av psykosociala insatser. Att undersöka effekterna av psykosociala 
insatser och inte deras effektivitet kräver ett bredare angreppssätt än det som förekommer i kunskapssammanställningen.

I och med omtolkningen av uppdraget från "efficacy" till "efficency" inträffar en betydelsefull glidning. I sin ursprungliga definition definierades evidensbaserad medicin genom en avvägning mellan forskningsresultat, klinisk erfarenhet och brukarnas önskemål (Sackett et al. 2000). IMS:s kunskapssammanställning fokuserar endast på ett av dessa tre fält. Det är inte längre de reellt existerande verksamheterna som står i fokus för sammanställningen, utan den forskningsmetod som verksamheternas effektivitet har undersökts med. De insatser som inte dokumenterats med rätt forskningsmetod finns inte; oberoende deras resultat för brukarna. Men dessa insatser har haft en effekt. Om deras effekter får vi inget veta, då de beforskats med "fel« metod.

\section{Erfarenhet och kunskap inom socialt arbete}

Kommunerna i Sverige har en över hundraårig tradition att arbeta med människor med allvarliga psykiska störningar (Sjöström 1992, Berge 2007). I samband med avinstitutionaliseringen har en bred flora av alternativ utvecklats såväl inom landsting som kommun. Utanför de slutna institutionerna har verksamheter och mottagningar med psykosocial inriktning vuxit fram: Dagverksamheter, boenden, boendestöd, verkstäder, träfflokaler mm. I samband med minskningen av den slutna vårdens omfattning kom kommunerna att spela en alltmer betydelsefull roll. Men om dessa verksamheter finns inget att säga. Expertgruppen konstaterar att:

"För två vanligt förekommande insatser, boendestöd och daglig sysselsättning, saknas resultat från systematiska forskningsöversikter och där finns således ett stort forskningsbehov."(s. 98)

Dessa verksamheter har dock följts upp och beforskats. Rapporter, utredningar och uppsatser samt artiklar i vetenskapliga tidskrifter och akademiska avhandlingar har publicerats (se exempelvis Andersson 2007 \& 2009, Denhov 2000b, Hansson 1997, Toll \& Schale 2007). Även om detta material är av skiftande kvalitet, så finns det en omfattande kunskapsmassa om dessa verksamheter. De utgör kunskap i stort behov av att summeras och analyseras. Och så skulle uppdraget ha kunnat tolkas med en bredare innebörd. De kunde ha tagit ställning till exempelvis Rose et al:s förslag (2006) när de pläderar för »....a multiple perspectives paradigm to integrate these varied sources of evidence» (s. 112) och för "multi-methods research" (s. 113).

Det var expertgruppens uppdrag att ta fram kunskap om deras effekt. Expertgruppen valde att sätta en metodologisk avgränsning för det fält som skulle undersökas. Andra val kunde ha gjorts. Risken med den metodfetischism som utvecklats inom delar av rörelsen för en evidensbasering av insatserna inom psykiatrin och socialtjänsten är att alla berörda hamnar i den välkända situationen med mannen som, en mörk natt, letar efter sina borttappade nycklar under en lyktstolpe. En förbipas- 
serande stannar och hjälper honom att leta. Efter en stund frågar den förbipasserande om det verkligen var under lyktstolpen som mannen tappat sina nycklar, varpå denne svarar att han hade tappat sina nycklar i en gränd i närheten, men där var det så mörkt att det blev för svårt att leta. Den inomvetenskapliga diskussionen om vad som är evidens är långt ifrån avgjord, och kommer troligtvis aldrig att avgöras.

Det borde vara acceptabelt att olika metoder lämpar sig för olika frågor och olika perspektiv (Rose et al. 2006). Socialpolitiska reformer, mellanmänskliga relationer och sammansatta verksamheter är tre exempel på frågeområden som inte kan undersökas med randomiserade kontrollerade studier. Att begränsa våra frågor till dem som kan besvaras med denna och endast denna forskningsmetod får förödande konsekvenser. I "Sammanställningen" framskymtar denna diskussion endast i förbifarten och tämligen oproblematiserad. På sidan 102 kan man läsa:

"Således kan den insats som skall undersökas inverka på val av studietyp, vilket $i$ nästa led kan påverka vad som inkluderas $i$ en översikt. Även andra kontrollerade studier än de med RCT-design kan ge värdefull information, inte minst $i$ ett utvecklingsskede av en viss insats."

En sida senare återkommer expertgruppen till samma frågeställning och skriver: "Här får man vara öppen för att också värdera resultaten från forskning med annan design än RCT-studier« (s. 103). Tyvärr leder inte dessa reflektioner till någonting i expertgruppens praktik. Det finns därmed en uppenbar risk för att en omfattande praktik och dess utvärderingar inte kommer att återspeglas i de kommande riktlinjerna.

De medikaliserande avgränsningarna som väglett arbetet med kunskapssammanställningen ger den en skev och svag grund som är problematisk när den publiceras av en statlig myndighet. Arbetet ger därför också en skev och svag grund för framtagningen av riktlinjer för psykosociala insatser för människor med allvarliga psykiska störningar och funktionsnedsättningar. Dessa riktlinjer kommer att vara vägledande för de kommande årens satsningar på detta område. De kommer att utgöra den officiella ramen för det som anses vara goda psykosociala insatser. Återigen riskerar kartan att bli viktigare än landskapet. Erfarenheterna som görs dagligen av personal och brukare inom olika psykosociala och socialpsykiatriska verksamheter osynliggörs och den evidens som presenteras blir haltande.

Medikaliseringen av det psykiatriska fältet har analyserats tidigare (Foucault 1972, Scull 1981, Conrad \& Schneider 1992, Conrad 2007). Den har aktualiserats på nytt i samband med den s.k. Psykiatrireformen. Under senare år har "samverkan" betonats $\mathrm{i}$ många sammanhang, men har ofta framställts som socialarbetarnas övertagande av psykiatrins kunskapsbas, språk och tankefigurer inom ramen för en "nationell kunskapsstyrning". IMS:s kunskapssammanställning är ett tydligt exempel på denna process och bör problematiseras. De arbetssätt som utvecklats i den sociala praktiken kommer inte in i de statliga myndigheternas kunskapssammanställningar därför att de anses vara utvärderade på 
fel sätt. Därmed tas inte heller denna erfarenhetskunskap med i arbetet med Nationella Riktlinjer. Vilket får till följd att olika beställarorganisationer och verksamhetsledningar inte kommer att beställa denna typ av insats och satsar inte på denna typ av verksamhet. Dessa erfarenheter tas inte heller tillvara på offentliga utbildningsinstitutioner och på sikt riskerar denna genuina kunskapsutveckling att upphöra inom det psykosociala fältet. Detta riskerar att förhindra en önskvärd utveckling av evidensbaserade insatser för människor med en psykosocial problematik.

\section{Referenser}

Andersson, G. (2007) Uppföljning av Kravatten - en verksamhet för unga vuxna med psykisk ohälsa. Stockholm: Hägersten och Liljeholmens stadsdelsförvaltning. Stockholms stad.

Anderson, G. (2009) Vardagsliv och boendestöd - en studie om människor med psykiska funktionshinder. Rapport i Socialt Arbete nr 131. Stockholm: Stockholms Universitet, Institutionen för socialt arbete.

Anttila, S. (2007a) „Svar på replik från Bergmark och Lundström». Socialvetenskaplig Tidskrift, 14:4, s. 312-316.

Anttila, S. (2007b) „Slutord». Socialvetenskaplig Tidskrift, 14:4, s. 322-323.

Bentall, R. (1990) »The syndromes and symptoms of psychosis. In R. Bental (ed.) Reconstructing schizophrenia, London: Routledge.

Bentall, R. (2003) Madness explained. Psychosis and human nature. London: Allen Lane.

Berge, A. (2007) Sjukvårdens underklass. Umeå: Boréa Bokförlag.

Bergmark, A. \& Lundström, T. (2006) "Mot en evidensbaserad praktik? - Om färdriktningen i socialt arbete». Socialvetenskaplig Tidskrift, 13:2, s. 99-113.

Bergmark, A. \& Lundström, T. (2007a) „Replik. Kartan och terrängen - Om evidensbaserad praktik som ideal och verklighet». Socialvetenskaplig Tidskrift, 14:1, s. 77-82.
Bergmark, A. \& Lundström, T. (2007b) „Om metaanalyser som styrmedel i socialt arbete». Socialvetenskaplig Tidskrift, 14:4, s. 312-316.

Bleuler, M. (1978) The schizophrenic disorders - Long-term patient and family studies. New Haven and London: Yale University Press.

Blomqvist, J. (1996) „Paths to recovery from substance missuse; change of lifestyle and the role of treatment». Substance Use and Misuse, 31 (13), pp. 1807-1852.

Blomqvist, J. (1999) Inte bara behandling - vägar ut ur alkoholmissbruket. Stockholm: FoU-rapport 1999:16.

Borg, M. \& Kristiansen K. (2004) "Recoveryorientated professionals: Helping relationships in mental health services". Journal of Mental Health, 13 (5), pp. 493-505.

Borg, M. \& Davidson, L. (2007) The nature of recovery as lived everyday experience, Journal of Mental Health, 17 (2), pp 129-140.

Bourdieu, P. (2004) Science of science and reflexivity. Cambridge: Polity Press.

Boyle, M. (2002) Schizophrenia - A scientific delusion? $2^{\text {nd }}$ edition. London: Routledge.

Burns, T. (2009) End of the road for treatment-asusual studies? The British Journal of Psychiatry 195: 5-6.

Conrad, P. (2007) The medicalization of society. Baltimore: The John Hopkins University Press. 
Conrad, P. \& Schneider, J. (1992) Deviance and medicalization - From badness to sickness. Philadelphia: Temple University Press.

Davidson L., Haglund K., Stayner D., Rakfeldt J., Chinman M. \& Kraemer Tebes J. (2001) „I was just realizing... that life isn't one big horror': A qualitative study of supported socialization". Psychiatric Rehabilitation Journal, vol. 24 no 3, pp. 279-292.

Davidson L., Shahar G., Stayner D.A. Chinman M.J., Rakfeldt J. \& Kraemer Tebes J. (2004) "Supported socialization for people with psychiatric disabilities: lessons from a randomized controlled trial«. Journal of Community Psychology, vol 32, no 4, pp. 453-477.

Denhov, A. (2000a) Personalens bidrag till aterhämtning: Ett brukarperspektiv. Rapport 11. 2000. Stockholm: VSSO, FoU-enheten/psykiatri.

Denhov, A. (2000b) Relation som produkt. - Arbetsoch sysselsättningsverksamheter för psykiskt funktionshindrade. Samverkansrapport 2. 2000. Stockholm: VSSO, FoU-enheten/psykiatri, FoU Socialtjänsten Stockholm..

Denhov, A. (2002) „Finns kvar och ställer upp. Hur kan anhöriga bidra till àterhämtning från allvarlig psykisk störning, ur de återhämtades och de anhörigas perspektivs. Stockholm: Underlagsrapport Anhörig 300, Socialstyrelsen.

Denhov, A. (2007) Hjälpande relationer i psykiatrisk vård - en litteraturöversikt. Stockholm: FoU-enheten. Psykiatrin Södra.

Elkin I., Shea T., Watkins J.T., Imber S.D., Sotsky S.M., Collins J.F., Glass D.R., Pilkonis P.A., Leber W.R., Dochert J.F., Fiester S.J. \& Parloff M.B. (1989) „National Institute of Mental Health treatment of depression collaborative research program - General effectivness of treatments». Arch Gen Psychiatry, vol 46, pp. 971-982.

Foucault, M. (1972) Histoire de la folie à l'age classique, Paris: Gallimard, (Svensk övers. 1983) Vansinnets historia under den klassiska epoken. Lund: Arkiv förlag.

Hansson, J. H. (1993) Organizing normality essays on organizing day activities for people with severe mental disorders. Linköping: Linköpings Universitet: Tema Hälsa och Samhälle.

Harding, C. \& Keller, A. (1998) »Long-term outcome of social functioning". In K. Mueser \& N. Tarrier (eds.) Handbook of social functioning in schizophrenia, Boston: Allyn and Bacom.

Hessle, S. (1985) Riktlinjer för psykosocialt arbete. Stockholm: Norstedts Förlag.

Hydén, M. (2008) „Evidence based social work att sammanställa systematiska kunskapsöversikter». Socialvetenskaplig Tidskrift, Vol 15, nr 1, s. 3-19.

Illich, Ivan (1975) Medical Nemesis: The Expropriation of Health. London: Calder \& Boyars.

Johannisson, K. (1990) Medicinens öga. Sjukdom, medicin och samhälle - historiska erfarenheter, Stockholm: Norstedt.

Johansson, H. (2006) Therapeutic alliance in general psychiatric care. Lund: Lund University, Dep of Psychology \& Lund University Hospital: Division on Psychiatry.

Kirk, S. \& Kutchins, H. (1992) The selling of the DSM. The rhetoric of science in psychiatry. New York: Walter de Gruyter.

Lambert, M. J. (2004) Bergin \& Garfield's Handbook of psychotherapy and behavior change (Fifth edition). New York: John Wiley \& Sons.

Lee P., Lieh-Mak F., Yu K. \& Spinks J. (1993) "Coping strategies of schizophrenic patients and their relationship to outcomer. British Journal of Psychiatry, vol. 163, pp. 177-182.

Lennér-Axelson, B. \& Thylefors, I. (1999) Psykosocialt behandlingsarbete. Stockholm: Bokförlaget Natur och Kultur.

Luborsky L. Diguer L., Seligman D., Rosenthal R., Karuse E., Johnson S., Halperin G., Bishop M., Berman J. \& Sweizer (1999) »The researchers own therapy allegiance: A wild card in comparisons of treatment efficacy". Clinical Psychology: Science and practice, 6, pp. 95-106.

Mattsson M., Topor A., Cullberg J. \& Forsell Y. (2008) "Association between financial strain, social network and five-year recovery from first episode psychosis». Soc Psychiatry Psychiatr Epidemiol, vol 43, pp. 947-952.

McCabe, R. \& Priebe, S. (2004) »The therapeutic 
relationship in the treatment of severe mental illness: a review of methods and findings". International Journal of Social Psychiatry, vol 50 (2), pp. 115-128.

Nationalencyklopedin (1994) Psykisk störning, Femtonde bandet. Höganäs: Bokförlaget Bra Böcker.

Pettersen, G. (2007) Eating disorders. Studies of understanding and recovery. Trondheim: Doctoral Theses at NTNU, 2007:245.

Read, J. (2004a) „Does 'schizophrenia' exist? Reliability and validity". In J. Read, L. R. Mosher \& R. P. Bentall (eds.) Models of madness. Psychological, social and biological approaches to schizophrenia. New-York: Brunner-Routledge.

Read, J. (2004b) "Poverty, ethnicity and gender". In J. Read, L. R. Mosher \& R. P. Bentall (eds.) Models of madness. Psychological, social and biological approaches to schizophrenia. NewYork: Brunner-Routledge.

Rose D., Thornicroft G. \& Slade M. (2006) „Who decides what evidence is? Developing a multiple perspectives paradigm in mental health". Act Psychiatr Scand 113, Suppl 429, pp. 109114.

Sackett D.L., Strauss S.E., Richardson W.S., Rosenberg W. \& Haynes R.B. (2000) Evidence based medicine. How to practice and teach EBM $\left(2^{\text {nd }}\right.$ ed.). London: Churchill Livingstone.

Sandlund, M. (2005) "Vad är psykiskt funktionshinder?" In D. Brunt \& L. Hansson (red.) Att leva med psykiska funktionshinder - livssituation och effektiva vaird och stödinsatser. Lund: Studentlitteratur.

Schön, U-K. (2009) Kvinnors och mäns återhämtning från psykisk ohälsa, Rapport i Socialt Arbete nr 130. Stockholm: Stockholms Universitet, Institutionen för socialt arbete.

Schön, U-K, Denhov, A. \& Topor, A. (2009) Social relationships as a decisive factor in recovering from severe mental illness, International Journal of Social Psychiatry, 55 (4), 336-347.

Schreiber, R. (1996) "(Re)defining my self: Women's process of recovery from depression". Qualitative Health Research, vol. 6. No 4, pp. 469-491.
Scull, A. T. (red.) (1981) Madhouse, mad-doctors and madmen. The social history of psychiatry in the Victorian era. Philadelphia: University of Pennsylvania press.

Sjöström, B. (1992) Kliniken tar över dårskapen - Om den moderna svenska psykiatrins framväxt. Uddevalla: Daidalos.

Socialstyrelsen (1998) Den sociala vardagen - En studie av 115 verksamheter för personer med psykiska funktionshinder. Psykiatri uppföljningen 1998:4. Stockholm: Socialstyrelsen.

Socialstyrelsen (2006a) Effekter av psykosociala insatser för personer med schizofreni eller bipolär sjukdom - en sammanställning av systematiska översikter. Stockholm: IMS.

Socialstyrelsen (2006b) Handikappomsorg. Lägesrapporter. Stockholm: Socialstyrelsen.

SOSFS (2000) Socialstyrelsens föreskrifter och allmänna råd om psykiatrisk tvångsvaird och rättspsykiatrisk vaird, SOSFS 2000:12. Stockholm: Socialstyrelsen.

SOU (1992) Välfärd och valfrihet - service, stöd och vård för psykiskt störda, SOU 1992:73.

SOU (2006) Ambition och ansvar. Nationell strategi för utveckling av samhällets insatser till personer med psykiska sjukdomar och funktionshinder. SOU 2006:100.

Sundgren, M. (2007) "Att bygga en monolit». Psykisk Hälsa, nr 3 .

Thornicroft, G. \& Tansella, M. (2002) „Mental health services research". In S. Priebe \& M. Slade (eds.) Evidence in mental health care. Hove and New-York: Brunner-Routledge.

Toll, B. \& Schale (2008) En väg till återhämtning. Visby: BoD.

Topor, A. (2004) Vad hjälper? Vägar till återhämtning från svåra psykiska problem. Stockholm: Natur och Kultur.

Topor A., Borg M., Mezzina R., Sells D., Marin I. \& Davidson L. (2006) "Others: The role of family, friends and professionals in the recovery process". American Journal of Psychiatric Rehabilitation. Vol 9, nr 1, pp. 17-37.

Turner E.H., Matthews A.M., Linardatos E., Tell R.A. \& Rosenthal R. (2008) "Selective publication of antidepressant trials and its influence 
on apparent efficacy". The New England Jour-

nal of Medicine, 358:3, pp. 252-260.

Wampold, B.E. (2001) The Great Psychoth-

erapy Debate - Models, Methods and Findings.

Mahwah: Lawrence Erlbaum Associates, Inc.

Warner, R. (1985) Recovery from schizophrenia -
Psychiatry and political economy. New-York: Routledge \& Kegan Paul.

Åsberg, M. (2000) „Placebo inom psykiatrin». In H. Boström \& H. Dahlgren (red.) Placebo. Stockholm: Liber/SBU.

\section{Summary}

\section{The medicalization of the psychosocial domain On a summary of the state of knowledge by the National Board of Health and Welfare, IMS}

The empirical part of this article is a description of the process of gathering the content of what was to be an exhaustive summary of the current state of knowledge. The summary was commissioned by the Swedish National Board of Health and Welfare and was to concern the effects of psychosocial interventions for persons with severe disabilities in their mental and emotional functioning.

A working group was formed with participants mainly from medical faculties in Sweden. No professors of social work or psychology were asked to participate in compiling the knowledge summary or reviewing the final report.

During the course of the work, the target group was changed to comprise "persons with schizophrenia and bipolar illnesses", thus modifying the definition from a social perspective to a diagnostic, medical perspective. The working group also subsequently changed its commission to summarize the research on effects to now concern research on effectiveness, operationationalized primarily through randomized control studies. The group thus did not find any acceptable studies despite the many areas in which exten- sive research is being conducted. Furthermore, the concept of "psychosocial interventions" was limited to a few arbitrarily chosen examples of individual treatment interventions. The summary ignores alliance and placebo research, studies on the importance of a basic economy for mental health and studies on such social-policy interventions as housing and labour market policy decisions.

Nor does the report mention the problems discussed in connection with evidence-based interventions such as the difference between efficacy and efficiency, the role that the researcher's allegiance has for the results obtained, the context of the results and the lack of evidence whereby the application of evidence-based methods could attain more acceptable results.

The report lacks critical distance to its own work, with respect to the definition of key concepts and to the choice of which studies to include. A major part of research on psychosocial interventions has thereby become invisible in a report with an obvious ideological bias. Despite this serious limitation, the knowledge summary is intended to form the basis for future government guidelines for the psychosocial domain. 